Pacific Journal of Mathematics

WHITEHEAD GROUPS OF TWISTED FREE ASSOCIATIVE
ALGEBRAS 


\title{
WHITEHEAD GROUPS OF TWISTED FREE ASSOCIATIVE ALGEBRAS
}

\author{
Koo-GUAN ChOo
}

Let $R$ be an associative ring with identity and $X$ a set of noncommuting variables $\left\{x_{\lambda}\right\}_{\lambda \in \Lambda}$. Let $R\{X\}$ be the free associative algebra on $X$ over $R$. Then S. Gersten has shown that if $K_{1} R \rightarrow K_{1} R[t]$ is an isomorphism, where $R[t]$ is the polynomial extension of $R$, then $K_{1} R \rightarrow K_{1} R\{X\}$ is an isomorphism.

The purpose of this paper is to extend the result of Gersten to twisted free associative algebras.

Let $R$ be an associative ring with identity and $X$ a set of noncommuting variables $\left\{x_{\lambda}\right\}_{\lambda \in \Lambda}$ and $\mathfrak{a}=\left\{\alpha_{\lambda}\right\}_{\lambda \in \Lambda}$ a set of automorphisms $\alpha_{\lambda}$ of $R$. The a-twisted free associative algebra on $X$ over $R$, denoted by $R_{\mathrm{a}}\{X\}$, is defined as follows:

Additively, $R_{\mathrm{a}}\{X\}=R\{X\}$ so that its elements are finite linear combinations of words $w\left(x_{\lambda}\right)$ in $x_{\lambda}$ with coefficients in $R$.

If $w\left(x_{\lambda}\right)=x_{\lambda_{1}} \cdots x_{\lambda_{k}}$ is a word in $x_{\lambda}$, we denote the automorphism $\alpha_{\lambda_{1}} \cdots \alpha_{\lambda_{k}}$ by $w\left(\alpha_{\lambda}\right)$.

Multiplication in $R_{a}\{X\}$ is given by:

$$
\left(r w\left(x_{\lambda}\right)\right)\left(r^{\prime} w^{\prime}\left(x_{\lambda}\right)\right)=r w\left(\alpha_{\lambda}\right)^{-1}\left(r^{\prime}\right) w\left(x_{\lambda}\right) w^{\prime}\left(x_{\lambda}\right),
$$

for any $r w\left(x_{\lambda}\right), r^{\prime} w^{\prime}\left(x_{\lambda}\right) \in R_{\mathrm{a}}\{X\}$.

In particular, if $X=\{t\}$ and $a=\{\alpha\}$, then $R_{\mathrm{a}}\{X\}$ is just the $\alpha$ twisted polynomial ring $R_{\alpha}[t]$.

We shall consider $R_{\mathrm{a}}\{X\}$ as an $R$-ring with augmentation $\varepsilon_{X}$ : $R_{\mathrm{a}}\{X\} \rightarrow R$ defined by $\varepsilon_{X}\left(x_{\lambda}\right)=0$ for each $x_{\lambda} \in X$. Denoted by $\bar{K}_{1} R_{\mathrm{a}}\{X\}$ the cokernel of the homomorphism $i_{*}: K_{1} R \rightarrow K_{1} R_{a}\{X\}$ induced by the inclusion $i: R \rightarrow R_{\mathrm{a}}\{X\}$. Note that the augmentation $\varepsilon_{X}$ induces a homomorphism $\varepsilon_{X^{*}}: K_{1} R_{\mathrm{a}}\{X\} \rightarrow K_{1} R$ which splits $i_{*}$.

Let $W(X)$ be the set of all the words $w\left(x_{\lambda}\right)$ in $x_{\lambda}$. For each $w\left(x_{\lambda}\right)$ in $W(X)$, let $\beta_{w}$ be the automorphism $w\left(\alpha_{\lambda}\right), h_{\beta_{w}}$ the homomorphism of $R_{\beta_{w}}[t]$ into $R_{a}\{X\}$ defined by $h_{\beta_{w}}(t)=w\left(x_{\lambda}\right)$ and $\bar{h}_{\beta_{w}}$ the homomorphism of $\bar{K}_{1} R_{\beta_{w}}[t]$ into $\bar{K}_{1} R_{\mathrm{a}}\{X\}$ induced by $h_{\beta_{w}}$. Then our main result is:

THEOREM 1. The group $\bar{K}_{1} R_{\mathrm{a}}\{X\}$ is generated by the homomorphic images of $\bar{K}_{1} R_{\beta_{w}}[t]$ under $\bar{h}_{\beta_{w}}$ and $w\left(x_{\lambda}\right)$ runs over $W(X)$.

As a consequence, we have:

THEOREM 2. (Twisted Case of Gersten's Theorem). If $K_{1} R \rightarrow$ $K_{1} R_{\beta_{w}}[t]$ is an isomorphism for each $\beta_{w}$, then $K_{1} R \rightarrow K_{1} R_{a}\{X\}$ is an 
isomorphism.

Now, let $A$ be an invertible matrix over $R_{\mathrm{a}}\{X\}$. By Higman's trick (cf. [4]), we can make $A$ equivalent in $K_{1} R_{a}\{X\}$ to

$$
B=B_{0}+B_{1} x_{1}+\cdots+B_{n} x_{n},
$$

where $x_{1}, \cdots, x_{n}$ are distinct elements of $X$ and $B_{i}(i=0,1, \cdots, n)$ are $m \times m$ matrices over $R$ for some integer $m$. By applying the homomorphism $\varepsilon_{X^{*}}$ to $B$, we deduce that $B_{0}$ is invertible. Hence $A$ can be made equivalent in $\bar{K}_{1} R_{a}\{X\}$ to

$$
N=I+N_{1} x_{1}+\cdots+N_{n} x_{n},
$$

where $N=B_{0}^{-1} B$ and $N_{i}=B_{0}^{-1} B_{i}(i=1, \cdots, n)$.

The inverse of this matrix $N$ can be written explicitly in the ring of formal power series. Since this inverse exists in $R_{\mathrm{a}}\{X\}$, all but a finite number of the power series coefficients are zero. That is, if

$$
M=M_{0}+M_{1} x_{1}+\cdots+M_{n} x_{n}+\sum_{i, j=1}^{n} M_{i, j} x_{i} x_{j}+\cdots
$$

is a matrix over $R_{\mathrm{a}}\{X\}$, where all $M_{i}, M_{i, j}, \cdots$ are matrices over $R$, such that $M N=N M=I$, then there is an integer $K>0$ such that $M_{i_{1}, i_{2}, \cdots, i_{k}}=0$ for all $k>K$, where $i_{1}, i_{2}, \cdots, i_{k}$ run over $1, \cdots, n$ respectively. From $N M=I$, we get, by equating coefficients of monomials in the $x^{\prime} \mathrm{s}$, the following relations:

$$
\begin{array}{lr}
M_{0}=I ; & \\
M_{i}=-N_{i} & (i=1, \cdots, n) ; \\
M_{i, j}=N_{i} \alpha_{i}^{-1}\left(N_{j}\right) & (i, j=1, \cdots, n) ; \\
\vdots & \\
M_{i_{1}, i_{2}, \cdots, i_{l}}=(-1)^{l} N_{i_{1}} \alpha_{i_{1}}^{-1}\left(N_{i_{2}}\right) \cdots\left(\alpha_{i_{1}}^{-1} \alpha_{i_{2}}^{-1} \cdots \alpha_{i_{l-1}}^{-1}\right)\left(N_{i_{l}}\right) \\
& \left(i_{1}, i_{2}, \cdots, i_{l}=1, \cdots, n\right) .
\end{array}
$$

Hence, for all $k>K$,

$$
N_{i_{1}} \alpha_{i_{1}}^{-1}\left(N_{i_{1}}\right) \cdots\left(\alpha_{i_{1}}^{-1} \alpha_{i_{2}}^{-1} \cdots \alpha_{i_{k-1}}^{-1}\right)\left(N_{i_{k}}\right)=0 .
$$

Let us call a matrix $P$ over $R \beta$-twisted nilpotent ( $\beta$ is any automorphism of $R$ ) if there exists an integer $k>0$ such that

$$
P \beta^{-1}(P) \cdots \beta^{-(k-1)}(P)=0 \text {. }
$$

Hence, it follows from (2) that each $N_{i}(i=1, \cdots, n)$ in (1) is $\alpha_{i}$ twisted nilpotent.

Our next lemma is the key to the main result: 
LEMMA 3. The matrix $N$ in (1) is a product of matrices of the form $I+P w\left(x_{1}, \cdots, x_{n}\right)$, where $P$ is an $w\left(\alpha_{1}, \cdots, \alpha_{n}\right)$-twisted nilpotent matrix over $R . \quad\left(w\left(x_{1}, \cdots, x_{n}\right)\right.$ denotes a word in $x_{1}, \cdots, x_{n}$.)

Proof. Recall from (1) and (2) that each $N_{i}(i=1, \cdots, n)$ in (1) is $\alpha_{i}$-twisted nilpotent. Consider

$$
I+Q=\left(I-N_{1} x_{1}\right) \cdots\left(I-N_{n} x_{n}\right) N .
$$

Then $Q$ is of the form $\sum_{j} Q_{j} s_{j}$, where $s_{j}$ is a monomial of degree at least two in the $x_{1}, \cdots, x_{n}$. In fact, if $s_{j}=x_{i_{1}} x_{i_{2}} \cdots x_{i_{l}}(l \geqq 2)$, then

$$
Q_{j}= \pm N_{i_{1}} \alpha_{i_{1}}^{-1}\left(N_{i_{2}}\right) \cdots\left(\alpha_{i_{1}}^{-1} \cdots \alpha_{i_{l-1}}^{-1}\right)\left(N_{i_{l}}\right) .
$$

Hence, for $k>K / 2$,

$$
Q_{j} \beta^{-1}\left(Q_{j}\right) \cdots \beta^{-(k-1)}\left(Q_{j}\right)=0,
$$

for each $j$, where $\beta$ is an automorphism obtained by replacing the $x_{i}$ in $s_{j}$ by $\alpha_{i}$ respectively. That is, $Q_{j}$ is $s_{j}\left(\alpha_{1}, \cdots, \alpha_{n}\right)$-twisted nilpotent for each $j$. Now, consider

$$
I+Q^{\prime}=\prod_{j}\left(I-Q_{j} s_{j}\right)(I+Q) .
$$

Then $Q^{\prime}$ is of the form $\sum_{\sigma} Q_{\sigma}^{\prime} y_{\sigma}$, where each $y_{\sigma}$ is a monomial of degree at least four in the $x_{1}, \cdots, x_{n}$ and for $l \geqq 4, Q_{\sigma}^{\prime}$ is of the form as given on the right hand side of (3). Thus, for $k>K / 4$,

$$
Q_{o}^{\prime} \gamma^{-1}\left(Q_{\sigma}^{\prime}\right) \cdots \gamma^{-(k-1)}\left(Q_{\sigma}^{\prime}\right)=0
$$

for each $\sigma$, where $\gamma$ is an automorphism obtained by replacing the $x_{i}$ in $y_{\sigma}$ by $\alpha_{i}$ respectively. That is, $Q_{\sigma}^{\prime}$ is $y_{\sigma}\left(\alpha_{1}, \cdots, \alpha_{n}\right)$-twisted nilpotent for each $\sigma$.

Left multiplying $I+Q^{\prime}$ by $\Pi_{\sigma}\left(I-Q_{\sigma}^{\prime} y_{\sigma}\right)$, and repeating the above argument, we will finally arrive, after a finite steps (because of the finite bound $K$ and condition (2)), at the conclusion that

$$
\Pi\left(I+P w\left(x_{1}, \cdots, x_{n}\right)\right) \cdot N=I,
$$

where $P$ is an $w\left(\alpha_{1}, \cdots, \alpha_{n}\right)$-twisted nilpotent matrix over $R$ and $w\left(x_{1}, \cdots, x_{n}\right)$ is a word in $x_{1}, \cdots, x_{n}$.

This completes the proof.

The above discussions are modifications of those given in [3] and ([1], p. 647) for (untwisted) free associative algebras; and the following result is already contained in the above proof (also cf. [2]). 
Lemma 4. For any automorphism $\beta$ of $R, \bar{K}_{1} R_{\beta}[t]$ is generated by the elements of the form $I+P t$, where $P$ is an $\beta$-twisted nilpotent matrix over $R$.

Proof of Theorem 1. It follows immediately from Lemmas 3 and 4.

\section{REFERENCES}

1. H. Bass, Algebraic K-Theory, W. A. Benjamin, Inc., New York, 1968.

2. H. Bass, A. Heller, and R. G. Swan, The Whitehead group of a polynomial extension, Publ. I. H. E. S. No. 22, (1964), 61-79.

3. S. Gersten, Whitehead groups of free associative algebras, Bull. Amer. Math. Soc., 71 (1965), 157-159.

4. G. Higman, The units of group rings, Proc. London Math. Soc., 46 (1940), 231-248.

Received October 18, 1972. This research was supported in part by a postgraduate fellowship of the National Research Council of Canada. It contains parts of the results from the author's doctoral thesis at the University of British Columbia written under the direction of Professor E. Luft. The author is most indebted to Professor E. Luft, and to Professor K. Y. Lam for their valuable suggestions and encouragement during the preparation of the thesis.

UNIVERSITY OF BRITISH COLUMBIA 


\section{PACIFIC JOURNAL OF MATHEMATICS}

\section{EDITORS}

RICHARD ARENS (Managing Editor)

University of California

Los Angeles, California 90024

\section{R. A. Beaumont \\ University of Washington \\ Seattle, Washington 98105}

\section{J. DugundjI*}

Department of Mathematics University of Southern California Los Angeles, California 90007

D. Gilbarg and J. Milgram

Stanford University

Stanford, California 94305

\section{ASSOCIATE EDITORS}
E. F. BeCKenBaCH
B. H. NeumanN
F. WOLF
K. YoSHIDA

\section{SUPPORTING INSTITUTIONS}

\author{
UNIVERSITY OF BRITISH COLUMBIA \\ CALIFORNIA INSTITUTE OF TECHNOLOGY \\ UNIVERSITY OF CALIFORNIA \\ MONTANA STATE UNIVERSITY \\ UNIVERSITY OF NEVADA \\ NEW MEXICO STATE UNIVERSITY \\ OREGON STATE UNIVERSITY \\ UNIVERSITY OF OREGON \\ OSAKA UNIVERSITY
}

\author{
UNIVERSITY OF SOUTHERN CALIFORNIA \\ STANFORD UNIVERSITY \\ UNIVERSITY OF TOKYO \\ UNIVERSITY OF UTAH \\ WASHINGTON STATE UNIVERSITY \\ UNIVERSITY OF WASHINGTON

$* * *$
$*$
AMERICAN MATHEMATICAL SOCIETY
NAVAL WEAPONS CENTER

The Supporting Institutions listed above contribute to the cost of publication of this Journal, but they are not owners or publishers and have no responsibility for its content or policies.

Mathematical papers intended for publication in the Pacific Journal of Mathematics should be in typed form or offset-reproduced, (not dittoed), double spaced with large margins. Underline Greek letters in red, German in green, and script in blue. The first paragraph or two must be capable of being used separately as a synopsis of the entire paper. Items of the bibliography should not be cited there unless absolutely necessary, in which case they must be identified by author and Journal, rather than by item number. Manuscripts, in duplicate if possible, may be sent to any one of the four editors. Please classify according to the scheme of Math. Rev. Index to Vol. 39. All other communications to the editors should be addressed to the managing editor, or Elaine Barth, University of California, Los Angeles, California, 90024.

100 reprints are provided free for each article, only if page charges have been substantially paid. Additional copies may be obtained at cost in multiples of 50 .

The Pacific Journal of Mathematics is issued monthly as of January 1966. Regular subscription rate: $\$ 60.00$ a year (6 Vols., 12 issues). Special rate: $\$ 30.00$ a year to individual members of supporting institutions.

Subscriptions, orders for back numbers, and changes of address should be sent to Pacific Journal of Mathematics, 103 Highland Boulevard, Berkeley, California, 94708.

PUBLISHED BY PACIFIC JOURNAL OF MATHEMATICS, A NON-PROFIT CORPORATION

Printed at Kokusai Bunken Insatsusha (International Academic Printing Co., Ltd.), 270, 3-chome Totsuka-cho, Shinjuku-ku, Tokyo 160, Japan

* C. R. DePrima California Institute of Technology, Pasadena, CA 91109, will replace J. Dugundji until August 1974. 


\section{Pacific Journal of Mathematics}

Vol. 50, No. $2 \quad$ October, 1974

Mustafa Agah Akcoglu, John Philip Huneke and Hermann Rost, A counter example to the Blum Hanson theorem in general spaces .............

Huzihiro Araki, Some properties of modular conjugation operator of von

Neumann algebras and a non-commutative Radon-Nikodym theorem

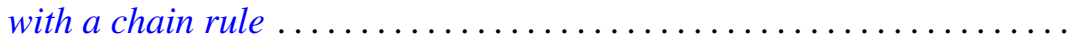

E. F. Beckenbach, Fook H. Eng and Richard Edward Tafel, Global properties of rational and logarithmico-rational minimal surfaces .....

David W. Boyd, A new class of infinite sphere packings ............. 383

K. G. Choo, Whitehead Groups of twisted free associative algebras ........

Charles Kam-Tai Chui and Milton N. Parnes, Limit sets of power series

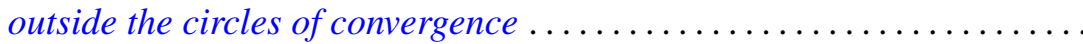

Allan Clark and John Harwood Ewing, The realization of polynomial

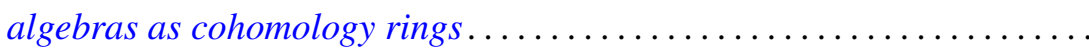

Dennis Garbanati, Classes of circulants over the p-adic and rational

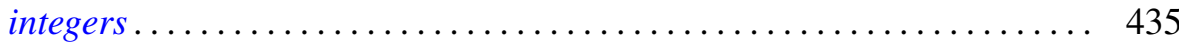

Arjun K. Gupta, On a "square" functional equation ................... 449

David James Hallenbeck and Thomas Harold MacGregor, Subordination and extreme-point theory ............................. 455

Douglas Harris, The local compactness of $v X \ldots \ldots . . . . . . . . . . . .4469$

William Emery Haver, Monotone mappings of a two-disk onto itself which fix the disk's boundary can be canonically approximated by homeomorphisms .................................. 477

Norman Peter Herzberg, On a problem of Hurwitz .................. 485

Chin-Shui Hsu, A class of Abelian groups closed under direct limits and subgroups formation ............................... 495

Bjarni Jónsson and Thomas Paul Whaley, Congruence relations and multiplicity types of algebras.....................

Lowell Duane Loveland, Vertically countable spheres and their wild sets.

Nimrod Megiddo, Kernels of compound games with simple components ....

Russell L. Merris, An identity for matrix functions ........ . .

E. O. Milton, Fourier transforms of odd and even tempered distributions ...

Dix Hayes Pettey, One-one-mappings onto locally connected generalized continua

Mark Bernard Ramras, Orders with finite global dimension

Doron Ravdin, Various types of local homogeneity. .

George Michael Reed, On metrizability of complete Moore spaces ...

Charles Small, Normal bases for quadratic extensions ..

Philip C. Tonne, Polynomials and Hausdorff matrices.... . . 